\title{
The Impact of COVID-19 on Agriculture Industry in U.S Stock Market
}

\author{
Yuhan $\operatorname{Jin}^{1, *}$ \\ ${ }^{1}$ Faculty of Economics, Shenzhen University, Shenzhen 518000, China \\ *Corresponding author. Email: 2018221003@email.szu.edu.cn
}

\begin{abstract}
Under the impact of the global outbreak of COVID-19, macroeconomic fluctuations have different degrees of effects on various industries. The outbreak of the new crown pneumonia epidemic has caused another negative impact on the already weak global economy. This paper analyzes the changes of American agricultural industry to explore the impact of this basic industry based on Fama French five factor model. This study selects the data from 2019.5.1 to 2020.2.28 as the data before the COVID-19 and 2020.3.1 to 2020.12.31 as the data after the appearance of COVID-19 in the U.S. The significance of five factors and the change of beta in 10 months before and after the epidemic are compared by multiple linear regression. According to the results, the market factor MKT of the agricultural industry did not change much, which was still less than 1. The market value factor SMB of the agricultural industry has changed from significant to insignificant. As for t-Stat of HML factor changed from 0.61 to 3.88, which turned to be significant during COVID-19. Moreover, RMW and CMA stayed redundant. Based on the analysis, this paper aims to evaluate the stocks of American agricultural companies suitable for investment in the epidemic stage. These results shed light for a reference of industry analysis and stock investment during the epidemic period.
\end{abstract}

Keywords: COVID-19, Agriculture, Fama-French Model, U.S. stock market

\section{INTRODUCTION}

In economic globalization, the impact of the COVID-19 on the global economy is faster and more severe than any crisis in history. The outbreak of the new crown pneumonia epidemic has caused another negative effect on the already weak global economy. In 2020, under the impact of the COVID-19, the real yield of U.S. Treasury bonds appeared in a state of continuous negative returns after more than 40 years once again. Besides, the U.S. economy has entered a state of negative interest rates. In the short term, the US's large-scale rescue measures have reduced the destructive effects of the epidemic on the economy and society, and effectively stabilized the panicked financial market. However, the US government's neglect and downplay of the epidemic in the early stage and the premature restart of the economy in the later stage weakened the effectiveness of epidemic prevention and control, leading to increased uncertainty in the economic outlook.

The capital asset pricing model is the first equilibrium model for the pricing of financial assets, which is also the first financial asset pricing model that can be measured and tested [1]. The primary significance of the model is to establish the relationship between capital risk and return, clearly indicating that the expected return rate of securities is the sum of the risk-free return rate and risk compensation, and revealing the internal structure of securities returns. Another important significance of the capital asset pricing model is that it divides risks into non-systematic risks and systemic risks. Non-systematic risk is a risk unique to a particular company or industry, which is a risk that can be diversified through asset diversification. Systematic risk refers to the risk factors that affect the entire market, which is the inherent risk of the stock market itself and cannot be eliminated through diversification. The role of the capital asset pricing model is to diversify non-systematic risks through investment portfolios, leaving only systemic risks. Additionally, the $\beta$ coefficient is introduced into the model to characterize the system risk.

Under the influence of the COVID-19 epidemic, 
important industries in health-related industries have once again been reflected. The measure to protect people's health plays a vital role in the smooth operation of the regional and even the world's economy. The path to prevent and control the epidemic while ensuring that the economy is not paralyzed is an important topic that countries need to study and explore.

Under the Fama-French model, there are related studies, Gomez and Lopez analyze the effect of cross-country differences in accounting standards on the empirical performance of financial pricing models. It shows how the lack of uniform accounting standards across countries generates inconsistent estimates of the model parameters, and leads to rejection of the validity of the model. As an empirical application, Gomez and Lopez analyze the differences in accounting standards affect the performance of the Fama-French (1993) three-factor pricing model. Auther shows that the F-F model is accounting-specific: it works better if the data are homogeneous in terms of accounting standards. This result has an important empirical corollary: the model accounts extremely well for the cross-country returns of firms following IASB standards. It has relevant policy implications that reinforce the convenience of accounting homogenization across countries [2]. Horváth and Wang evaluate the performance of Fama-French models on US stock markets during the selected events by metrics $\mathrm{R}^{2}$ scores of the models. Horvath and Wang find that the influence of Dotcom bubble to the $\mathrm{R}^{2}$ of growth model is statistically significant. The $\mathrm{R}^{2}$ of growth portfolios decreases rapidly during the Financial crisis of 2008. The latest COVID-19 outbreak drop has led to a substantial in the R2 during this event. Furthermore, Horváth and Wang find that all of the beta model parameters are insignificant in the GMM model [3]. Chen et al. divide market sentiment period into three states and select the securities in the Chinese stock market to construct portfolios [4]. Specifically, they implement both the Fama-French five-factor model and the robust median covariance matrix approach for predicting the expected return of the selected stocks and portfolio optimization respectively. Then they compare the performance of the portfolio constructed by the Fama-French three-factor model with that by the traditional covariance matrix in different market sentiment periods. The empirical results indicates that the performance of the portfolio constructed by the Fama-French five-factor model is more sensitive to the fluctuation of stock market sentiment. Moreover, robust median covariance matrix approach tends to have relatively stable portfolio return, while ineffective in the bull market. The main contribution of this paper is having empirically tested different model combinations in portfolio theory using the data of Chinese market where market sentiment has unique impact. To some extent, Chen et al provide a reference to the portfolio strategy [4]. Chowdhury attempts to test the functioning of Fama-French (FF) three-factor model at Chittagong Stock Exchange (CSE). The three factors include market risk premium, size risk and book to market risk. Nine portfolios are constructed by taking daily closing prices of thirty selective stocks of CSE from January 2010 to December 2014. Treasury bill rates of Bangladesh are used as a proxy for the risk-free rate. Chowdhury finds, stocks with small market capital outperform that of large market capital. It also observes that higher book to market ratio yields poor earnings. Although return at CSE is significantly influenced by rational size, it is weakly affected by value. Being a rumor driven and inefficient market, the FF model has positive but weaker explanatory capacity on stock returns at CSE [5].

Research on the impact of related industries is as follows. During the COVID-19 pandemic, online grocery shopping experienced a never seen popularity in many countries. To investigate the reaction of globally active online grocer Amazon Fresh to this extraordinary demand increase, Hillen and Judith analyzed a large dataset of daily price quotes for over 19,000 products for the customer location, Los Angeles. Hillen and Judith found that contrary to the US consumer food price index, the overall price level at Amazon Fresh did not increase during the pandemic, but even slightly decreased for several product groups. Amazon seems to follow its low-price strategy also in the grocery sector, even in times of high demand. However, during the lockdown phase, there were more price increases for certain highly demanded product groups such as frozen and prepared foods. Moreover, fewer prices were communicated as promotional prices. Because this change did not influence the general price level, it is concluded that such promotional prices are used more as a marketing tool than as a price-setting instrument.[6]

Relevant research on the impact of the U.S. stock market by the epidemic: Shu et al. employed the log-periodic power law singularity (LPPLS) methodology to systematically investigate the 2020 stock market crash in the U.S. equities sectors with different levels of total market capitalizations through four major U.S. stock market indexes [6]. During the 2020 U.S. stock market crash, all four indexes lost more than a third of their values within five weeks, while both the middle capitalization stocks and the small capitalization stocks have suffered much greater losses than the large capitalization stocks and stocks overall. The results indicate that the price trajectories of these four stock market indexes prior to the 2020 stock market crash have clearly featured the obvious LPPLS bubble pattern and were indeed in a positive bubble regime. Contrary to the popular belief that the COVID-19 led to the 2020 stock market crash, the 2020 U.S. stock market crash was endogenous, stemming from the increasingly systemic instability of the stock market itself [7]. The stock market provides a view of what investors expect 
for the future. It is precisely in complex situations such as the COVID-19 outbreak that the prescience of the market is particularly valuable, argues Alexander F. Wagner. The market foretells a different economic landscape than the one used to. Such changes bring potentially massive social and political upheavals. Hopefully, one can avoid the inherent dangers and benefit from the opportunities [8]. Capital is coward, money tends to flee the markets during crises periods. In just few days after declaring Coronavirus as a pandemic by the World Health Organization (WHO), major stock markets lost more than $15 \%$ of their market capitalization. AlAli aims to examine the velocity of Coronavirus pandemic effect on major stock markets during the early stages of the pandemic. The study also examines whether or not there was any difference before and after the first confirmed Coronavirus case reported. Based on the data on eleven major stock markets, results from this study shows that, out of the eleven markets under study, six markets showed no difference in mean return 30 trading days before and after reporting the first COVID-19 case in these countries. These results also showed that WHO announcement had a more impact on the stock markets performance than the announcements of local health authorities' announcements. One interesting finding in this research is that there was an inverse relation between the distance of the stock market from Wuhan and the financial performance of that market [9]. COVID-19 has had a much larger impact on the financial markets compared to previous epidemics because the news information is transferred over the social networks at a speed of light. Using Twitter's API, Goel et al compiled a unique dataset with more than 26 million COVID-19 related Tweets collected from February 2nd until May 1st, 2020. Goel et al find that more frequent use of the word "stock" in daily Tweets is associated with a substantial decline in log returns of three key US indices - Dow Jones Industrial Average, S\&P500, and NASDAQ. The results remain virtually unchanged in multiple robustness checks [10]. COVID-19 has affected the economy of almost every country in the world. Of particular interest are the responses of the economic indicators of developing nations (such as BRICS) to the COVID-19 shock. Bhattacharyya et al look at the same question with respect to the BRICS nations. Bhattacharyya et al use structural variable autoregression (SVAR) to identify the dynamic underlying associations across the normalized growth measurements of the COVID-19 cumulative case, recovery, and death counts, and those of the exchange rate, and stock market indices, using data over 203 days. According to impulse response analyses, the COVID-19 shock to the growth of exchange rate was seen to persist for around 10+ days, and that for stock exchange was seen to be around 15 days. The models capture the contemporaneous nature of these shocks and the subsequent responses, potentially guiding to inform policy decisions at a national level. Further, causal inference-based analyses would allow us to infer relationships that are stronger than mere associations [11].

Under the impact of the epidemic, agriculture fluctuates greatly. Meanwhile, as the primary industry, agriculture has a significant effect on people's lives and economic development. If agricultural production is unstable, it will have an impact on the economy of the United States and the world. Therefore, the purpose of this article is to use the Fama-French model to explore the impact on American agriculture under the influence of COVID-19.

\section{METHOD}

A study by Fama and French in 1992 on the factors that determine the difference in the return of different stocks in the US stock market found that the beta value of the stock market cannot explain the difference in the return of different stocks, while the market value, book-to-market ratio, and price-to-earnings ratio of listed companies can explain the difference in the rate of return of the stock[12]. Fama and French believe that the above-mentioned excess returns are compensation for risk factors that are not reflected by $\beta$ in CAPM. The mathematical expression is as follows:

$R_{i t}-R_{F t}=a_{i}+b_{i}\left(R_{M t}-R_{F t}\right)+s_{i} S M B_{t}+h_{i} H M L_{t}+e_{i t}(1)$

In Equation(1), $R_{i t}$ represents the return rate of stock portfolio $i$ at time $\mathrm{t} ; R_{F t}$ represents the risk-free rate at time $t$, expressed as the one-month treasury bond yield; $R_{M t}$ represents the return rate of the market portfolio weighted by market value; $S M B_{t}$ represents the return rate difference between a portfolio of companies with a low circulating market value and a portfolio of companies with a higher circulating market value; $H M L_{t}$ represents the return difference between a portfolio of value companies with a high book-to-market value ratio and a portfolio of growth companies with a low book-to-market value ratio in period $\mathrm{t}$; $e_{i t}$ represents residual difference.

Afterwards, Fama and French found that in addition to the above risks, there are also profit level risks and investment level risks that can also bring excess returns to individual stocks. Besides, they proposed a five-factor model in 2013. This model more fully explains the excess returns of individual stocks. The mathematical expression is as follows:

$$
\begin{gathered}
R_{i t}-R_{F t}=a_{i}+b_{i}\left(R_{M t}-R_{F t}\right)+s_{i} S M B_{t}+ \\
h_{i} H M L_{t}+r_{i} R M W_{t}+c_{i} C M A_{t}+e_{i t}(2)
\end{gathered}
$$

RMWt represents the difference between the return rate of a combination of companies with strong profitability and a combination of companies with poor profitability during $t$, in which profitability is the operating profit after deducting operating costs, sales expenses, financial expenses and management expenses 
from the operating income of the previous period measured by the ratio of the book value of the owner's equity in the previous period; CMAt represents the difference between the rate of return of a portfolio of companies with a low investment level and a portfolio of companies with a high investment level in period $t$, where the investment level is divided the growth of total assets in $\mathrm{t}-1$ period by the total assets in $\mathrm{t}-2$ period.

\section{RESULTS}

The data in this experiment are the daily income data of 38 industry classifications in the past two years and the factor data of the Fama-French five-factor model. This article intercepts the data from 2019.5.1 to 2020.2.28 as the data before the COVID-19 and 2020.3.1 to 2020.12 .31 as the data after the appearance of COVID-19 in the U.S. The reason is that although the epidemic broke out at the end of 19, the outbreak in the United States began to get out of control in March 20, and the emergence of vaccines was at the end of 20 years. Therefore, the experiment selected this stage as the research object. Under the Fama-French five-factor model, the experiment uses multiple linear regression to estimate and test the five-factor coefficients of the industry for two periods of time, comparing through experiments to reflect the impact of the epidemic on the industry. Among them, the changes in agriculture are the most obvious, i.e., the next experiment will take agriculture as the research object.

Table 1. Regression results of agriculture industry from 2019.5-2020.2

\begin{tabular}{ccccc}
\hline & Coefficients & S.D & t Stat & P-value \\
\hline Intercept & 0.01 & 0.10 & 0.11 & 0.91 \\
MKT & 0.96 & 0.12 & 8.28 & 0.00 \\
SMB & 0.70 & 0.22 & 3.22 & 0.00 \\
HML & -0.14 & 0.22 & -0.61 & 0.54 \\
RMW & 0.52 & 0.37 & 1.41 & 0.16 \\
CMA & 0.05 & 0.43 & 0.12 & 0.90 \\
\hline
\end{tabular}

Table 2. Regression results of agriculture industry from 2020.3-2020.12

\begin{tabular}{ccccc}
\hline & Coefficients & S.D & t Stat & P-value \\
\hline Intercept & 0.10 & 0.13 & 0.74 & 0.46 \\
MKT & 0.87 & 0.06 & 14.39 & 0.00 \\
SMB & 0.08 & 0.16 & 0.50 & 0.62 \\
HML & 0.50 & 0.13 & 3.88 & 0.00 \\
RMW & -0.09 & 0.26 & -0.36 & 0.72 \\
CMA & -0.36 & 0.33 & -1.08 & 0.28 \\
\hline
\end{tabular}

In the experiment, the market factor MKT of the agricultural industry did not change much, and the factor coefficient decreased from 0.96 to 0.87 , which was still less than 1. The parameter test indicates MKT is significant at the $95 \%$ confidence level, the null hypothesis is rejected. This factor is significant for the model in this experiment. The market value factor SMB of the agricultural industry has changed from significant to insignificant. As for t-Stat of HML factor changed from 0.61 to 3.88 , which turned to be significant during COVID-19. Moreover, RMW and CMA stayed redundant.

\section{DISCUSSION}

\section{1. $M K T$}

Although the impact of COVID-19 has affected the world's economy and various industries have been affected, the US agricultural industry's sensitivity to the market has further declined, and the coefficient of risk premium has dropped from 0.96 to 0.87 . The reasons are as follows. Agriculture, as a rigid demand product, has relatively low flexibility and relatively low market sensitivity. It is because the epidemic has stabilized people's demand for foo. In the meantime, many countries have issued bans on the export of certain grains in order to protect their domestic grain reserves. Kazakhstan, a major wheat flour exporter, has banned the export of wheat flour, carrots, sugar and potatoes, Vietnam has suspended the signing of new rice export contracts, and Serbia has banned the export of sunflower seed oil and other commodities during the period of COVID-19. On the other hand, Since the beginning of the epidemic, as many as 11 people have died of hunger and malnutrition every minute, and the proportion of people suffering from similar famine has increased sharply. By comparison, novel COVID-19 pneumonia is estimated to be 7 deaths per minute. Global food prices also rose by $40 \%$, the highest increase in more than a decade. For instance, the price of Brazil's main grains has continued to rise since last year. In one year, the price of rice has risen as high as $70 \%$, and that of corn has risen as high as $87 \%$. Among them, the price of corn in May is the highest record since 2004. All these factors keep the market factors of agricultural stocks stable.

\section{2. $S M B$}

The SMB coefficient test is significant with positive value before the outbreak of epidemic, indicating that small companies are more popular. The reason is that large-scale, large-market American agricultural companies are all necessary cash crops, and their profit margins are relatively fixed. On the other hand, many small market capitalization companies are cash crops with relatively high profit margins. With higher risk, buying a small market capitalization company is more profitable, i.e., the economic benefit of risk compensation is also high. Besides, Small market capitalization companies are more risky and have a certain risk compensation effect. While, the outbreak of 
the epidemic has caused a certain increase in the demand for food, which is a good behavior for both large and small companies. The raw materials produced in the U.S. agriculture have also been affected by the epidemic. Many small-scale agricultural companies have gone bankrupt. Only the agricultural giants still maintain stable production. Therefore, for the stocks of the entire food sector, the stock price has risen, i.e., the SMB factor has become redundant.

\section{3. $H M L$}

The HML factor was not significant before COVID-19. After COVID-19, HML has become significant and the coefficient value is positive, indicating that the return of value stocks is higher than that of growth stocks. The reason is that value stocks appear to be more rigidly needed in the epidemic. The fundamentals are relatively stable, and the world's demand for bulk agricultural products continues to increase, and the supply falls short of expectations. China as the largest exporter of U.S. agriculture. For instance, China's strong demand and global soybean demand are also showing a recovery trend. From 2020 to 2021, global soybean consumption will increase month by month, while the output will decline due to the continuous reduction of US soybeans and Argentina soybeans, and the gap will expand accordingly. USDA forecasts that the global soybean production for 20/21 in December is 362 million tons, a decrease of 586,000 tons from the previous month, a year-on-year increase of $2.4 \%$, of which Argentina's production is reduced to 1 million tons; the total global soybean consumption is expected to be 370 million tons, compared with the previous month An increase of 691,000 tons, an increase of $4.3 \%$ year-on-year; the annual balance-9.82 million tons, a decrease of 997,000 tons from the previous month. Under the influence of the epidemic, value stocks in the agricultural stock market are more valuable in contrast.

\section{4. $R M W$}

The RMW factors of the epidemic are redundant before and after, indicating that profitability is not the focus of investors in the two cities. The United States is a large grain production and export country. Mechanized operations have made US grain production relatively stable and profit levels are relatively stable.

\subsection{CMA}

Before and after the epidemic, CMA factor was redundant. The grain industry is a typical traditional industry. The market structure is relatively clear. After years of development, several grain production giants have emerged. The investment style in the grain industry does not cause too much attention from investment institutions.

\section{CONCLUSION}

In summary, this paper investigates the impact of COVID-19 on American agricultural industry before and after the outbreak as well as the severe fluctuation of macro-economy based on the Fama-French five factor model and multifactorial linear regression. Specifically, the market factor MKT of the agricultural industry remains stable, which was still less than 1 ; the market value factor SMB of the agricultural industry has changed from significant to insignificant; The HML factor changed from 0.61 to 3.88 , which turned to be significant during COVID-19. Moreover, RMW and CMA stayed redundant. It represents, agriculture, as a rigid demand product, has relatively low flexibility and relatively low market sensitivity. Furthermore, the outbreak of the epidemic has caused a certain increase in the demand for food, and the value stocks are more rigidly needed in the epidemic. These results offer a guideline for industry analysis and stock investment during the epidemic period.

\section{REFERENCES}

[1] Sharpe, W.F. (1964) Capital Asset Prices: A Theory of Market Equilibrium under Conditions of Risk. The Journal of Finance, 19, 425-442.

[2] GOMEZBISCARRI, J., \& LOPEZESPINOSA, G. . (2008). The influence of differences in accounting standards on empirical pricing models: An application to the Fama-French model. 18(4), 369-388.

[3] Horváth, D., \& Wang, Y. (2020). The examination of Fama-French Model during the COVID-19., $101848-$

[4] Chen, X., Song, P., Gao, K., \& Qiao, Y. (2017). The Application in the Portfolio of China's A-share Market with Fama-French Five-Factor Model and the Robust Median Covariance Matrix. 5(4), 222-.

[5] Chowdhury, E. (2017). Functioning of Fama-French Three-Factor Model in Emerging Stock Markets: An Empirical Study on Chittagong Stock Exchange, Bangladesh. 06(04), 352-363.

[6] Hillen, J. (2020). Online food prices during the COVID-19 pandemic.

[7] Shu, M., Song, R., \& Zhu, W. (2021). The 'COVID' Crash of the 2020 U.S. Stock Market.

[8] Wagner, A. (2020). What the stock market tells us about the post-COVID-19 world. 4.0(5.0), 440-440.

[9] AlAli, M. (2020). Risk Velocity and Financial Markets Performance: Measuring the Early Effect 
of COVID-19 Pandemic on Major Stock Markets Performance.

[10] Goel, R., Ford, L., Obrizan, M., \& Sharma, R. (2020). COVID-19 and the stock market: evidence from Twitter.

[11] Bhattacharyya, R., Rama, S., Kumar, A. , \& Banerjee, I. . (2021). Dynamic Structural Impact of the COVID-19 Outbreak on the Stock Market and the Exchange Rate: A Cross-country Analysis Among BRICS Nations.

[12] Fama, E.F. and French, K.R. (2004) The Capital Asset Pricing Model: Theory and Evidence. Journal of Economic Perspectives, 18, 25-46. 